\title{
A case study of records management practices in historic motor sport
}

\author{
Author Details: \\ Dr. Pauline Joseph \\ Curtin University \\ Corresponding author: As above \\ Corresponding Author's Email: p.joseph@curtin.edu.au
}

Department of Information Studies, School of Media Culture and Creative Arts, Curtin University, Perth, Western Australia

\section{Acknowledgments (if applicable):}

The author acknowledges funding from the Confederation of Australian Motor Sport Ltd (CAMS) and by the Centre for Sport and Recreation Research (CSRR) at Curtin University.

The author thanks the CAMS Historic Chairperson, WA for his guidance and support for the research. The author also thanks all the participants for their cooperation and support both at CAMS and the VSCC.

\section{Biographical Details (if applicable):}

Pauline Joseph (PhD) is a Lecturer in Records and Archives Management at the Department of Information Studies at Curtin University. Pauline studies how information is perceived and used in organisations and communities. With this focus in mind, she completed her PhD at the University of Western Australia in 2011, studying how knowledge workers search for corporate information in electronic document and records management systems (EDRMS). Her PhD research is titled "EDRMS search behaviour: implications for records management practices". Pauline's current research interests are about the sustainability of communitybased information management practices using the motor sport community as a case study. Further interests include research about understanding the concept of 'information' using the draw-and-write research technique and visual arts methodology.

\section{Structured Abstract:}

Purpose: This paper reports on empirical research that investigated the records management practices of two motor sport community-based organisations in Australia.

Design/methodology/approach: This multi-method case study was conducted on the regulator of motor sport, the Confederation of Australian Motor Sport Ltd (CAMS) and one affiliated historic car club, the Vintage Sports Car Club (VSCC) in Western Australia. Data was gathered using an online audit tool and by interviewing selected stakeholders in these organisations about their organisation's records management practices.

Findings: The findings confirm that these organisations experience significant information management challenges, including difficulty in capturing, organising, managing, searching, accessing and preserving their records and archives. Hence, highlighting their inability to manage records advocated in the best practice Standard ISO 15489. It reveals the assumption of records management roles by unskilled members of the group. It emphasizes that community-based organisations require assistance in managing their information management assets.

Practical implications: The research highlights risks to the motor sport community's records and archives. It signals that without leadership by the sport's governing body, current records and community archives of CAMS and its affiliated car clubs are in danger of being inaccessible, hence lost.

Social implications: The research highlights the risks in preserving the continuing memory of records and archives management in leisure based community organisations and showcases the threats in preserving its cultural identity and history.

Originality/value: It is a first study examining records management practices in the serious leisure sector using the motor sport community.

Keywords: Archives, Australia, ISO 15489, Information Management, Records Management, Community-based information management practices, 
Type header information here

For internal production use only

Running Heads: 


\section{A case study of records management practices in historic motor sport}

\section{Introduction}

Not-for-profit community-based organisations, associations, and clubs fill specialist niches in providing cultural, historical, sporting, health and philanthropic support to members of the community. They are extremely diverse: sporting clubs, churches, schools, historical associations, and ethnic groups all belong to this category of organisation. Flinn (2007) defines community-based organisations as 'communities that have shared or common beliefs, values, purpose and interests. They are grouped by locality, culture, faith, and background. Their identities differ by gender, occupation and ethnicity' (p. 153). Usually these community-based organisations rely upon the volunteer support of its membership, but some have paid staff as well.

The information assets of community organisations comprise records and archives in different media, including 'collections of material that encapsulate a particular community's understanding of its history and identity ... personal photographs, documents, ephemera and oral history, "unofficial" records that might not normally be preserved, let alone widely available' (Flinn, 2007, p. 32). These assets include paper and electronic documents, records, physical objects, memorabilia, photographs, oral and video recordings, web-based and social media information, including records of short-term or temporary retention value such as business records. The importance of these records lies in the significant role that community organisations play in the cultural fabric of broader society. By witnessing to and documenting the activities of these different communities, records and archives are 'the very essence of our heritage ... the direct, uninterrupted and authentic voice of the past' (Flinn, 2007, p. 152).

Despite the continuing memory value, cultural significance, and historical importance of community archives, there is limited understanding of the records management practices of community-based organisations in the sports leisure sector. Yet 'sport is one of the defining cultural pastimes and interests in Australia' (Crook, 2013, p. 295). This gap in the records management literature was a motivator to explore how records are managed in the serious leisure activity (Stebbins, 2007) of motor sport. 


\section{Background to the research}

This study focuses on the motor sport community in Australia, a community that not only has its roots in local areas but also has a strong national presence. Motor sport is one of the most popular sports in Australia. In 2014 the Confederation of Australian Motor Sport Ltd. (CAMS), the national body and the regulator for motor sport racing in Australia, supported 1,391 clubs and 6,247 events at amateur level (CAMS, 2014b, p. 12). CAMS is a 'not-for-profit member-based organisation focused on the development, regulation and administration of motor sport across Australia' (CAMS, n.d.). Approximately 150,000 people participate in motor sport across Australia annually; of these, 55,339 people compete only, 3,619 people compete and officiate, 17,419 people officiate only, and 76,775 are other club members (CAMS, 2014b, p. 10). Although spectators are additional participants at these events, this study focuses on the organisations, including competitors, volunteers, officials, and those with a deeper interest in and commitment to these organisations and the broader motor sport community.

This research concentrates on historic car clubs that are affiliated at the national level to CAMS, for two reasons. First, given the complexity of the types and certifications of vehicles involved in historic racing, this group has greater requirements for archival value records and tend to have more rigorous records management practices than clubs in the other motor sport disciplines. Second, there are concerns about how historic motor sport information is currently managed. These concerns emerged in discussions with the CAMS' historic panel chairperson (hereafter the Chairperson) in Western Australia who is also a committee member of the Vintage Sports Car Club (VSCC), a key informant with over four decades of experience in competitions and organisation of motor sport clubs in Australia (CAMS Chairperson, 2013). The chairperson highlighted significant information management challenges historic car clubs encounter in Australia, and requested assistance in addressing these challenges. Before assisting these clubs, it was decided to determine their current records management practices - another motivator for this research that led to the research question and the focus of this article:

Q) What are the records management practices of the motor sport community's CAMS national office and its historic car clubs in Australia? 
This approach aimed to understand the records management practices of the regulator of motor sport, CAMS, and five of its affiliated historic car clubs, one from each state in Australia.

To set the context for this research, an introduction to motor sport as a serious leisure sport is provided, including a description of the literature concerning motor sport. This is followed by an overview of the literature of records management practices in communitybased organisations.

\section{Motor sport: context}

Motor sport is a global sport with various race disciplines; each has its own national and international race meeting events. Knight and Torre (2013) report that Formula One (F1) races are the most watched sport in the world, with 500 million viewers a year. In 2014, F1's revenue was estimated at AUD $\$ 1.63$ billion, generated from race promoters' fees, broadcasting fees, sponsorships and corporate hospitality (Knight and Torre, 2013). In New South Wales, the 2015 Bathurst 1000 bicentennial year event of V8 Supercars was attended by 201,416 people over four days (van Leeuwen, 2015). Event organisers report 200,000 in ticket sales for 2015 (van Leeuwen, 2015). This event brought in about AUD\$5.25 million per day across four days and contributed AUD $\$ 55$ million to the state's economy (van Leeuwen, 2015).

It is amazing that 'in the expansive body of literature examining sport and globalisation that there is almost no mention of motor sport' in the peer-reviewed literature (Hassan, 2011, p. 187). A special issue of The International Journal of the History of Sport explored, analysed and explained the significance of motor sport in some countries globally. Its nine articles by several scholars provide an overview of how the sport varies from country to country, like the Dakar Rally and its impact on the environment, and the social responsibility of the sport (Hassan and O'Kane, 2011). O'Kane (2011) offers a historical overview of the 'triple crown' of motor racing events such as the Indianapolis 500, Le Man 24 Hours and the Monaco Grand Prix. Shackleford (2011) offers an overview of stock car racing, now known as NASCAR.

Motor sport, particularly motor racing, can be described as a pyramid of levels of participant involvement (Figure 1).

[Figure 1]

Page 3 of 26 
The top of the pyramid is F1. It comprises 20 to 25 professional participants who each drive for a professional team of 200 to 500 members or employees. The next level holds professional international drivers who compete in events like Le Mans 24 Hours. They comprise about 2000 drivers with professional teams traditionally of 20 to 30 members. The national level competitions have approximately 20,000 professional drivers with teams of 10 to 20 members. In Australia, approximately ten motor national racing (circuit) competitions are held in a majority of the states; there are traditionally 100 to 150 competitors in each state with teams of five to ten members. The next level down is the state and club level amateur drivers (all disciplines) and amateur volunteers. This includes historic racing and its impressive historic car clubs, the subject of this research. 'The Australian motor sport industry includes and supports: 334 tracks and venues; 1,391 clubs and 6,247 events' (CAMS, 2014, p. 12). The lowest level of the pyramid includes fans, spectators and social participants - about 6,000,000 people in Australia, of whom about 3.5 million watch all or part of the television broadcast of the Bathurst 1000, a national event with international competitors by invitation (Seven West Media Limited, n.d.).

Apart from the drivers/competitors in motor sport '17,419 licenced volunteer officials in Australia ... are responsible for running the majority of motor sport events' (CAMS, 2014 b, p. 2). The reliance on volunteers for officiating, administering and promoting the sport is international (Harrington, Cuskelly and Auld, 2000). A proportion of the top level officials are paid, whilst the remainder do it for love of the sport at their own cost of money and time. Land-based motor sport in Australia predominantly comes under the jurisdiction of CAMS.

Some literature has concentrated on different aspects of motor sports or other leisure activities, but none is on the management of community-based information, which is of interest in this research. For example, Pflugfelder (2009) examined gender differences, such as women drivers in a male-dominated sport; and Ross, Ridinger and Cuneen (2009) discussed the success of women like Indy driver Danica Patrick who endorse products through their expertise and attractiveness. Dannefer $(1980,1981)$ reported that historic car collectors are not 'mere car enthusiasts but passionate enthusiasts' whose interest dominates their leisure thoughts and activities (1981, p. 397). They engaged in showing, touring, collecting, restoring, and dealing historic cars (Dannefer, 1981, p. 397). There is also growing research interest in genealogy and family history (Fulton, 2009; Yakel, 2004); online museum 
visitors (Skov, 2013); and music records collectors (Margree et al., 2014), but the focus tends to be on personal information management. There is a distinct lack of research literature globally in motor sport, specifically in records management that maps how individual motor sport community-based organisations manage their information assets, both records and archives. The closest mention is by Cashman (2001), on how library materials in the broader sports discipline are managed in Australia; but this is not records management. Crook (2013) provides an overview of how sports archives are managed by libraries, archives and museums at a national level in Australia by information management professionals, but not of how they are managed by amateur community-based organisations.

Community-based organisations include community groups, clubs and other cultural associations. The information assets that these groups accrue are often reflective of the broader society, and can provide invaluable insight into the ways that groups, their members, interests and activities, have developed across time (Newman, 2010). These communities, which can be 'geographically based, or relate to a cultural or thematic community of interest' (Mander, 2009, p. 32), have archives which are

collections of material that encapsulate a particular community's understanding of its history and identity. This will often be personal photographs, documents, ephemera and oral history, 'unofficial' records that might not normally be preserved, let alone widely available (Mander, 2009, p. 32).

Archives consist of records which can be defined as 'information created, received, and maintained as evidence and as an asset by an organisation or person, in pursuit of legal obligations or in the transaction of business" (International Organisation for Standardisation, 2016, p. 2). Some records have temporary retention value derived from legislation affecting the organisation, whilst others are archives that should be permanently retained. As Cashman (2001) noted,

Sport archives provide records relating to much more than sport - they illuminate a whole host of other subjects including military history, social, economic, cultural and political history, the use of public land and so forth (p. 94). These benefits warrant the implementation of a records management programme to manage these information assets and provide measures for benchmarking information practice.

The core governance principles specified in Part 1 of ISO 15489 are applicable to community-based organisation's records management programmes (SAI, 2016, 2002):

Page 5 of 26 
- managing records stipulated by regulatory legislation;

- implementing a framework with strategies, policies and procedures for records management;

- assigning staff with recordkeeping responsibilities;

- training staff on recordkeeping practices; and

- monitoring and auditing compliance with the records management programme.

To investigate the records management practices of the historic motor sport community for this paper, an audit of current practices against 15489 standard was conducted.

\section{Research methodology}

As this research focuses on a specific community and how it manages its information assets, a multiple case study approach was selected, involving five historic motor sport car clubs, to provide evidence of current information practices in the motor sport community and ensure robust findings (Yin, 2014, p. 57).

Case studies explore a bounded system or case (Creswell, 2013, p. 97) over time through detailed, contextual, in-depth data collection involving multiple sources of information but focused on a specific object of study (Merriam, 2009, p. 40); they are particularly appropriate when investigating human behaviour in a real-life context (Yin, 2009, 2012, 2014).

This exploratory study was conducted within an interpretivist framework (Creswell, 2013) to allow for inductive analysis and the interpretation of meanings behind individuals' actions (Williamson et al., 2002). It involved several data collection strategies: semistructured one-on-one interviews and an online audit tool. Column 1 (Table 1) lists the research question; Column 2 identifies the participants involved; and Column 3 specifies the research tools used that enabled triangulation of the data (Table 1). The following sections explain how the research participants were selected, what research tools were used, and how data was collected and analysed.

[Table 1] 


\section{Participants}

Internationally, motor sport is governed by the Federation Internationale de l'Automobile (FIA) (Figure 1). CAMS is the national regulator in Australia, and all organisations that host official motor sport events, including motor cycle, speedway, carts and drag racing, are affiliated with CAMS (CAMS, n.d.). Approximately 460 clubs are affiliates and run their competitions in accordance with a permit issued by CAMS. Drivers and other competitors-who must be members of at least one affiliated club-hold a competition licence issued by CAMS (CAMS, 2014b).

[Figure 2]

Competitors are often members of more than one car club. Multiple memberships provide greater options and flexibility in participating in more and varied events. Figure 3 is a snapshot of the individual member's relationship with various clubs and CAMS. While staff at national and state offices are paid, as are some administrative staff of car clubs, most clubs are run by volunteers.

[Figure 3]

Table 1 show that participants in this research came from the CAMS national office and VSCC, a CAMS-affiliated historic car club.

The historic panel chairperson is a member of both of CAMS and VSCC, who assisted in the capacity of the informant by scheduling meetings, introducing participants and clarified questions the researcher had.

The CAMS national office is located in Melbourne and has 35 employees (CAMS, 2014a). CAMS's state offices were not included as they have limited full-time staff resources and limited records management practices; in addition, they participate in a separate records inventory exercise (not reported in this paper).

Once historic motor sport clubs were selected for this research for the reasons stated earlier, the aim was to understand the records management practices of the regulator of motor sport that is CAMS and five of its affiliated historic car clubs, one in each state in Australia.

With the assistance of the chairperson and the CAMS Australian historic motor sport commissioner, five clubs (one from each Australian state) were identified for potential 
participation in this research. These five clubs were sent letters of invitation to participate, and were subsequently contacted via phone and email:

- Historic Sports and Racing Car Association of NSW (Inc.) (HSRCA),

- South Australian Sporting Car Club (SASCC),

- Vintage Sports Car Club of WA Inc. (VSCC),

- Victorian Historic Racing Register (VHRR), and

- WA Sporting Car Club Inc. (WASCC).

Four of the five clubs agreed to participate, but only the VSCC completed the records management audit exercise and participated in the interview session.

Tools

This study involved two research tools to collect data: a records management audit tool and an interview questionnaire. Given interviews were conducted on onsite at CAMS, a tour of the office facilities where the participants' workstations and records were housed was conducted, as well. The author is familiar with the VSCC's clubhouse where the library is housed from prior social events organised there.

\section{Audit tool - Records and Information Management Doctor}

The free online Records and Information Management Doctor (RIM Doctor) (https://www.rimdoctor.com.au/) (Corporate information Management Services, (CIMS) 2014) was used to conduct the audit of the records management practices of the CAMS national office and the VSCC.

RIM Doctor was selected for three reasons. First, it is closely aligned with ISO 15489 (SAI, 2016, 2002) the international standard for records management best practices, ideal when benchmarking organisations during an audit (CIMS, 2014). Second, it was developed for application to smaller organisations, making it suitable for applying to community-based organisations. Third, it provides a quantitative measure of the level of compliance with ISO (SAI, 2016, 2002), allowing for a comparison of organisational practices against the Standard. Apart from these, RIM Doctor was selected for practical reasons relating to data collection. Originally the research was designed to audit six organisations across five different Australian states, but without the necessary time and budget to travel to each organisation to conduct the audits in person. 
Although RIM Doctor offers benefits in conducting an online audit, it requires a person knowledgeable about the records management practices of their organisation to respond to the questions: results are therefore subject to the bias of the respondent. This is a limitation that needs to be taken into consideration when comparing compliance with ISO 15489.

To complete the RIM Doctor audit for their respective organisations, CAMS nominated its historics coordinator whilst VSCC nominated its immediate past club president (Table 1).

\section{Interview questions}

One-on-one interviews were conducted with nine participants, seven from CAMS and two from the VSCC; each lasted approximately 30 minutes (See Appendix 1). The objectives of these interviews were to become familiar with the staff, learn where their records are housed, and gain an understanding of their views of records management practice in their organisation.

The seven nominated CAMS participants were from different business areas (see Table 1). The two interview participants from VSCC were the immediate past club president (hereafter referred as the president) and the club secretary; the president completed the online audit for the club. The interview with these VSCC representatives focused on their views of records management practices in their organisation and included a broad direction: Comment on the records and archives management practices at your car club.

\section{Data collection}

Following the approval of this study by the researcher's university ethics board, data collection for the audit exercise and interviews took place in March and April of 2014. Interview data were collected at CAMS over three days in March when the researchers, the author and two research assistants visited the national office. The assistants took handwritten notes whilst the researcher conducted the interviews. Interviews with the two VSCC representatives were conducted at the residence of the chairperson in April by the researcher, who also took notes.

For RIM Doctor, a letter was emailed to CAMS and the VSCC introducing the researcher, the research aims, the requirements, and a link to the audit tool. Detailed 
instructions were provided on how to access, complete and generate an audit report from RIM Doctor and email it to the researcher.

\section{Data analysis}

The audit data were analysed automatically by RIM Doctor, generating quantitative and qualitative analyses of how the compliance of each organisation's practices compared with ISO 15489.

The researcher combined the interview notes by the assistants with her own notes in preparation for the interview analysis. In keeping with the study's interpretivist framework, interview data were analysed inductively. This involved looking for evidence and answers from the data that would explain the participants' experiences, challenges, views, and visions about records management practices at their organisations that would answer the research question (Yin, 2014). Yin (2014) describes this as 'working ... data from the ground up' to 'pour [pore] through' the data looking for answers (pp. 136-137), which are used directly to interpret answers to the research question.

\section{Findings}

RIM Doctor's measurement of records management compliance

A detailed report (CIMS, 2014a, 2014b) generated by RIM Doctor explained how CAMS and VSCC performed against the Standard (SAI, 2016, 2002). This 23-page report for each organisation outlined the actions and steps needed to address compliance with the Standard, so both organisations received comprehensive recommendations on how to implement a records management programme, with an explanation of the benefits such a programme would provide.

Representatives tasked with completing the online audit on behalf of their organisations commented how it created awareness about records management and made them recognise gaps in current practices. One asked, 'could we have some records management please'.

The shaded areas in Figure 4 indicate how the organisations measured against six factors specified in ISO 15489: managing records stipulated by the regulatory environment; having strategies, policies, assigned responsibilities and procedures for managing corporate 
records; and monitoring and auditing records management practices (SAI, 2016, 2002). The larger the shaded area, the better the organisation performed.

[Figure 4]

In the RIM Doctor reports (CIMS, 2014a, 2014b) both organisations showed a low level of compliance in managing the security, access and use of records (SAI, 2016, 2002).

Figure 5 shows how both organisations measured in the day-to-day management of their records: creating records and capturing them in records systems; registering and classifying records into records systems; storing and handling records; applying appropriate access and security controls to records, systems, facilities and people; managing the retention and disposal of records; and tracking records.

[Figure 5]

Figure 6 indicates the measurement each organisation achieved for its records management programmes, training staff and others in making, keeping and using records; quality of records; documenting records management processes, controls and systems; and records systems.

[Figure 6]

RIM Doctor quantitatively and qualitatively confirmed that CAMS's and VSCC's governance of their records management programmes and practices are not compliant with ISO 15489 (Figure 7), both falling far short.

[Figure 7]

There are two possible explanations for VSCC being more compliant than CAMS in its records management practices. This could depend on the operational scale of VSCC compared to CAMS; or it might reflect the perceptions of the representatives who completed the audit assessment. 
More importantly, this finding highlights the need for planning and implementing records management programmes for each of these organisations. Policies and procedures need to be developed that document processes for capturing, classifying, registering, accessing, retaining, disposing of, and preserving corporate records; then management systems need to be implemented that allow relevant staff and members to capture and register their records for corporate use. Once these systems are in place, staff and committee members need to be trained to use them. After three years, it would be timely to add strategies to audit and monitor the performance of this programme. These steps would enable both organisations to better capture their corporate records, which in turn would allow efficient access to their records by authorised personnel.

RIM Doctor's assessment that current records management practices were inadequate was verified by the interviews conducted.

\section{Records management practices of CAMS from interviews}

The staff we interviewed were between the ages of 20 and 40. From the interviews (Q1, Q2 and Q6) it is evident that they were social media and tech-savvy, comfortable working with mobile devices and with electronic or digitised information; they embraced new information and communications technologies.

All indicated a desire to work with an electronic document and records management system (EDRMS), referred in the scenario in Q8 (see Appendix 1). They were keen to work in a digital office using a workflow system and mobile devices (Q7). Most favoured implementation of a workflow system for forms and information management. Some had worked in organisations with good information management systems, and had an appreciation of the benefits they provided. They recognised the ease of searching for information on electronic systems rather than in paper-based infrastructures. Depending on their work tasks, the time spent searching for information varied.

The staff were eager to have a client relationship management (CRM) system implemented. They perceived benefits in information that is organised in a central repository, including the easy collaboration it provided. Generally, staff recognised the need for an information management professional on their team, and saw the value it would provide CAMS and its clubs.

During the interviews it was learned that the implementation of a CRM system, part of the SharePoint 2010 suite of applications, had begun earlier that year (Q6). Some departments in CAMS had begun to migrate electronic information stored in network drives 
into the CRM system. The information technology manager confirmed that except for the default functionalities (checkin, checkout, version control, audit trail), no records management functionalities were included in the SharePoint implementation.

The interviewees reported that network drives were used as default records management systems (Q5). The general structure of the shared drive was not standardised so each user changed and added information to suit their preference and work tasks. Generally, the staff acknowledged that the shared drive provided a poor user experience (Q4 and 5) as there was no version control functionality, which they perceived to be important. They reported it was time-consuming to search for information stored on the network drive and in paper-based systems, and that it took much longer to search and collate technical information content. One staff member commented, 'the more technical the content the harder it was to find it' (Q3).

Inactive paper-based historic and technical archival records were housed in quality folders and stored in compactus shelving (Q4). The historics and technical motor sport coordinators reported that as they constantly referenced these records, they were stored onsite. Inactive paper-based records that were not history-related were stored off-site with a commercial storage provider; the majority of these were financial records with content listings, but it was reported that there were no content listings for the non-financial boxes stored off-site, and thus staff had limited knowledge of what these boxes held.

\section{Records management practices of VSCC}

The VSCC is an historic motor sport promoter with over 350 members, operating from facilities at the Caversham Motor Raceway in Brabham, Western Australia. It has a traditional committee system with subcommittees responsible for such things as competition, fiscal management, and social and community liaison. Its charter is to recreate Round The Houses Motor Racing, a style of street racing common in Western Australia in the post-war era. Mainly volunteer labour is used to organise and promote the two major events of this type each year, plus a mixture of other competitions in motor sport disciplines such as hill climb, sprint, motorkhana and regularity races at fixed or temporary road circuits and venues. Additionally, it has an in-house group of dedicated hands-on volunteer personnel who tackle the restoration and repair of competition vehicles and perform maintenance of their modest club facilities. 
The VSCC facility houses a small library and is used for committee meetings and social functions. The archives collection had to be moved from there to the home of the archivist when state government funding for the premises gatekeeper ceased in 2015, making the storage of these valuable archives on-site insecure. A committee member has been nominated to as librarian and another as club historian cum archivist. The library and archives collection are listed in an MS Excel spreadsheet maintained by the librarian.

The records management practices of the VSCC conform to the CAMS' historic panel chairperson's earlier observations about practices at other clubs:

Not all car clubs have dedicated common club house facilities to operate their sporting activities from or to house their archives. Hence, the club's operations are conducted from the homes of the elected committee members and at times from the homes of the relevant club members. This means, the information assets of the car club are scattered and are not transferred to the new committee members. This poses another challenge of losing critical information assets when the role of the treasurer or secretary changes at the annual elections. The Chairperson added that at times, club members are appointed to assist with motor sport event coordination and promotion, but do not always hand over the correspondence files when tasks are completed. This leads to problems of knowledge loss when new members are tasked to coordinate the same events later. The negotiations by the club representative with event stakeholders like town councils, sponsors and promoters are lost or not easily accessible (Joseph, 2015).

\section{Discussion}

The findings of this survey show that the records management practices of the two motor sport organisations studied do not comply with recommended best practices in the international standard AS/ISO 15489.

Since 2014, CAMS has initiated steps to implement an information technology infrastructure that includes a CRM with a SharePoint backend solution. This is a positive step in its information management. A closer review of the CRM and SharePoint infrastructure needs to be conducted to ensure SharePoint is implemented well and does not end up as disorganised as many generic network drives do. 
The current CRM has document management functionalities but not records management functionalities for classification or retention. SharePoint changes with each new version, and recent upgrades mean that it now has records management functionalities and does not require add-ons from third party traditional EDRM software; however, an audit is needed to ensure SharePoint is robust for electronic records management.

Given the governance role of CAMS in regulating motor sport, its business activities are managed using various forms for different applications. The event-centric nature of race meetings necessitates extra form management as a standard business activity, and it is highly recommended that a workflow module to the SharePoint system be added to structure the flow of information requests and approval processes. Records management classification schemes and a record retention period could be automatically implemented in these workflow settings as well.

The event-centric nature of motor sport information suggests that the system would benefit from a calendar interface to present upcoming events. Included in this interface should be links that fulfil information needs about registration for events, where an event is held, travel, accommodation and logistics information, format of the event, rules, results, etc. The system should also provide an opportunity for users to download event details for saving in their online diaries.

As the interviews revealed, CAMS national office stores some of its inactive records offsite and not all their contents are known. Contents listings are prepared only for financial records. This makes information retrieval from offsite storage difficult and expensive, as incorrect boxes may be retrieved and it may take a long time to find the required information. An audit of these boxes needs to be conducted, followed by an appraisal of their records. It is also likely that retention periods have not been assigned to these records. The business risks to CAMS from incompletely recorded and hard to access material include ongoing expenditure for offsite storage and exposure to legal risks resulting from the retention of records that could be destroyed.

The VSCC has neither the resources nor the funds to have a records management infrastructure like the CAMS national office for its recordkeeping. However, as this study reveals, the national office of CAMS has SharePoint with a CRM implementation. This finding is important as it opens discussion on whether CAMS is willing and able to extend this system to its affiliated clubs to address their current information management challenges. Further, it raises the question of whether car clubs would subscribe to this proposition. 
Conversations regarding how confidentiality of each club's information is secured needs to be had. For example, clubs require assurance that their information is only accessible to their individual club as clubs compete with each other for race meetings and funding. More importantly the confidentiality of members' personal information need that includes the vehicle assets they own need to be maintained. Also, confidentiality agreements needs to be in place on how clubs withdraw their information from the CAMS infrastructure when they are no longer affiliated with CAMS.

Information professionals are well aware that information assets need to be appraised, accessioned, arranged and described so that they can be accessed by anyone. The lack of such recordkeeping and archives tasks is preventing the motor sports community from accessing, searching, and retrieving this information (Bettington, Elberhard, Loo, \& Smith, 2008). As the CAMS historic chairperson noted, the community is finding it challenging to work with and access information stored in paper format and prefer it either digitised or in electronic format (2013).

The risks to community-based organisations' recordkeeping activities are exacerbated by the fact that affiliated car clubs like the VSCC do not have dedicated common club house facilities to operate their sporting activities from, or to house their archives in; often operations are conducted from the homes of members. The information assets of these car clubs are usually scattered (CAMS Historic Panel Chairperson, 2013). This poses a danger of losing critical information assets when a club treasurer or secretary changes, as some archives may not be transferred to new committee members. At the VSCC, often 'individual club members are appointed to assist with motor sport event coordination and promotion but they do not always hand over correspondence files when the tasks are completed' (CAMS Historic Panel Chairperson., 2013). This leads to problems of knowledge loss when other members are tasked to coordinate similar events later but records of negotiations by club representatives with event stakeholders such as town councils, sponsors and promoters have been lost or are not easily accessible. Sometimes unique club material like the design layout of race tracks or artwork for event advertisements held by individuals may be lost after their death because their value is not recognised.

In reviewing the records management experiences of the motor sport community, it becomes evident that this community-based organisation experiences key information management challenges which may be common to other such organisations (Joseph, 2015): 
- difficulty in sourcing, organising and managing (sometimes dispersed or lost) records and archives

- challenges in accessing past information or precedents to guide future practice

- inconsistent information management practices within a single community-based organisation, the result of different people assuming the role in an unregulated context

- lack of guidelines or principles to follow

- assumption of roles by unskilled members

- lack of awareness about information management professional standards (SAI, 2016, 2002)

- absence of a national service to assist in guiding good practice

- lack of awareness of guidelines and assistance available from cultural institutions.

These challenges are consistent with the author's observations in working with other community-based organisations, that many community groups faced considerable difficulties in capturing, managing and accessing their information assets. At times the volunteers or those tasked with managing the archives were not able to appraise the significance of their information, know what metadata are required to describe their collection adequately, or how best to register their collection (paper or electronically). Like the VSCC, these organisations reported using MS Excel spreadsheets to list their collections. They generally lacked knowledge about electronic records and archives systems to manage their information assets. In the absence records management expertise some community groups already digitising their records had the misguided expectation that the originals could then be destroyed. They were unaware of the decisions they needed to make before embarking on a digitisation project: why to digitise and what to digitise; whether it is to be a once-off retrospective or ongoing digitisation; whether the digitisation should be in-house or outsourced; what should happen to the paper records once they are digitised; what rules and standards for scanning should be followed; how images are registered in the scanning software; who owns copyright; what are the digitisation processes; and how quality checks will be performed (Joseph, May, \& Gregg, 2013). Even more importantly, they are inexperienced at considering how they will manage their newly digitised electronic information assets in the absence of established records management frameworks: that is, of policies, procedures and EDRM systems to store and manage the contents. How will long-term preservation of these archives in electronic format be maintained and managed? 
The data gathered in this study provide a descriptive overview of the lack of robust records management practices in the two motor sport organisations studied in Australia, which in turn gives insights into the potential information management issues faced by other motor sport organisations and similar community-based organisations (Hawkins \& Blake, 2013). These communities are struggling because they cannot afford to recruit information professionals to implement records management programmes that will enable them to manage their information assets according to best practice. Nor can they afford to acquire, design and operate complex computing systems to manage these ongoing assets. This problem is compounded at times by lack of support from senior management teams overseeing specific community interests. These communities struggle to manage their current information; often they are neither skilled nor in a position to plan for its long-term preservation. These factors frequently result in inadequate management of their information assets by volunteers or administrative assistants who are untrained in information management, and whose best efforts but bad practices are reflected in the capture, description, storage, and preservation of information assets on paper, in electronic form, and as artefacts. This later leads to information-seeking issues within the community and potential loss of their history.

In particular, the two motor sport organisations studied find it difficult to source their heritage information. They rely on word of mouth and the memories of past leaders to recall past experiences or knowledge at a time of need; when the elders die, their knowledge and information is lost forever. Even what is written may be lost if their descendants fail to realise the archival importance of boxes of old papers stashed in garages or attics.

\section{Conclusion}

This research investigates the current records management practices of two motor sport community-based leisure organisations. RIM Doctor indicates where each organisation is with its records management practices (Figures 4 to 7 ). The findings confirm that the records management practices at CAMS and VSCC are not ideal and need to be improved to comply with ISO 15489 principles for managing records. Essentially, these organisations need to implement robust processes and systems for creating, capturing and managing their records and information assets. Recruiting professionals with records and archives management expertise needs to be given high priority to achieve excellence in their recordkeeping practices.

Page 18 of 26 
The findings confirm the absence of compliant records management systems and processes in both CAMS and VSCC, which is evident from the RIM Doctor audit results. Both organisations do not have systems in place to consistently create, capture, use, share, access and preserve its information assets. CAMS with its CRM implementation attempts to address its information management practices. However, information management expertise is required to guide them achieve this. VSCC recognises its records management issues but is unable to afford systems and expertise to implement sustainable recordkeeping practices. Strategies for improving records management practices for CAMS and VSCC are presented in an upcoming paper being peer-reviewed, which compliments findings reported in the peerreviewed article titled Australian motor sport enthusiasts' leisure information behavior (Joseph, 2016).

This research further provides insight into the challenges faced with regard to information management in two community-based leisure organisations, raising the question of how other similar organisations manage their information assets. The lessons learned from this investigation have implications for other community-based organisations, society, the records management practice, and for teaching in the records management field of knowledge. Each of these implications are discussed below.

Other community-based organisations experiencing challenges with their records management practices may be comforted that they are not alone. Hopefully, this article will encourage them to conduct an audit of their records management practices using RIM Doctor, a tool that has the following advantages:

- It is free and is available online.

- It is not invasive.

- It is easy to understand.

- It does not require much time and effort.

- It automatically generates an assessment report of the organisation's records management practices.

- It provides strategies to improve recordkeeping practices.

It is recommended that a senior ranking member like the president, treasurer or club secretary is assigned to complete the audit exercise so that decision makers:

- understand the benefits of good records management programmes,

- have an awareness of what their organisation is missing in terms of records management, and

Page 19 of 26 
- $\quad$ are empowered to do what needs to be done.

More importantly, it is hoped that this article provides these organisations with confidence in how their records management challenges can be rectified.

Another key lesson learnt from this study is the need for organisations to find out what their parent organisation and affiliated organisations have implemented for records management, and to consider if resources, systems and space could be shared for sustainable records management practices within their wider affiliated organisations. For example, in this case study the SharePoint system implemented at CAMS might be extended to support affiliated car clubs with their records management practices. Likewise, a qualified records manager could be hired by CAMS with a mandate to provide services to affiliated clubs. Organisations need to contact their national or state cultural institutions to find what assistance can be provided to help manage their information assets. A potential lesson for the records management professional practice is that community-based organisations, like government and private sector organisations, have a need for good records management programs, if they are not to experience the information challenges described in this article. However, there is greater focus in the current records management discipline and profession on government and private sector organisations. This is evident in the number of standards and computing systems that are written and developed for larger organisations. The IT-02109 Project by Standards Australia has started to develop Handbook SA/SNZ HB 116 Recordkeeping for Small Businesses and Organisations. It is hoped that this project will address recordkeeping requirements for community-based organisations as described in this article. Similarly, vendors in the enterprise content management and electronic document management markets need to amend their current pricing structures to make it affordable and sustainable for community-based organisations to implement solutions to manage their information assets.

There are implications for teaching graduates in records management courses about the records management requirements and challenges in community-based organisations as well. Assessments that require students to base their studies in such organisations will enable graduates to gain an appreciation, first hand, of records management issues and possible solutions. These community-based organisations who offer students the opportunity to gain practical records management experience will benefit from the improved recordkeeping practices they will be given. 


\section{Appendix 1}

\section{Interview Questions for CAMS}

1. Do you use social media tools at work and home? If yes, what are these tools?

2. What mobile devices do you use at work and home?

3. How much time does it take you to search for information you need to do your work?

4. Are you satisfied with how you currently manage your information and work with it?

5. What is your experience working with the network drives?

6. What changes or improvements in information management would you like to happen?

7. Would implementing work flow system for managing requests submitted via forms assist you with actioning your tasks and managing these records?

\section{SCENARIO QUESTION:}

Would you like to work with a corporate electronic information management system that has workflow systems to process requests via forms; enables digitisation of paper based information; provides version control and audit trail of your information actions; allow authorised access to information resources; uses digital signatures and mobile technologies? Such a system would enable you to register, search, retrieve, retain, destroy and archive information as part of your business operation practices. The system would enable CAMS' affiliated clubs and members to access and submit information electronically, as well.

\section{References}

Bettington, J., Elberhard, K., Loo, R. and Smith, C. (Eds.). (2008). Keeping archives (3rd ed.), Australian Society of Archivists, Inc., Australian Capital Territory.

CAMS (The Confederation of Australian Motor Sport Limited). (2014a), CAMS organisational structure. Retrieved from: http://docs.cams.com.au/Corporate/Administration/Organisational\%20Structure\%20\%20January\%202015.pdf (accessed 12 February 2014).

CAMS (The Confederation of Australian Motor Sport Limited). (2014b), Economic contribution of the Australian motor sport industry. Retrieved from: http://docs.cams.com.au/Public\%20Documents/CAMS_EYReport_201014_LR.pdf (accessed 22 December 2014). 
CAMS (The Confederation of Australian Motor Sport Limited). (n.d.), History. Retrieved from: https://www.cams.com.au/about/about-cams/history (accessed 19 June, 2014).

CAMS Historic Panel Chairperson. (2013, 2 May 2013), [Letter to Dr Pauline Joseph at Curtin University from CAMS Historic Panel Chairman, regarding the Australian motor sport history archives].

Cashman, R. (2001), 'Sport Archives in Australia', Archives and Manuscripts, Vol. 29 No. 2, pp. 82-95.

CIMS (Corporate Information Management Services). (2014). The RIM Doctor: For healthier records and information. Retrieved from: https://www.rimdoctor.com.au/ (accessed 25 January 2014).

Corporate Information Management Services. (2014a). The RIM Doctor records and information management assessment for CAMS. Retrieved from Australia: https://www.rimdoctor.com.au/

Corporate Information Management Services. (2014b). The RIM Doctor records and information management assessment for CAMS. Retrieved from Australia: https://www.rimdoctor.com.au/

Creswell, J. W. (2013), Qualitative inquiry and research design: Choosing among five approaches (3rd ed.), SAGE Publications, London.

Crook, E. (2013), 'Sport and access to sport information in Australia', The Australian Library Journal, Vol. 62 No. 4, pp. 295-304.

Dannefer, D. (1980), 'Rationality and passion in private experience: Modern consciousness and the social world of old car collectors', Social Problems, Vol. 27 No. 4, pp. 392412. Retrieved from http://www.jstor.org.dbgw.lis.curtin.edu.au/stable/800167?origin=crossref\&seq=1\#pa ge_scan_tab_contents (accessed 16 December 2014).

Dannefer, D. (1981), 'Neither socialization nor recruitment: The avocational careers of oldcar enthusiasts', Social Forces, Vol. 60 No. 2, pp. 395-413. Retrieved from http://web.a.ebscohost.com.dbgw.lis.curtin.edu.au/ehost/detail/detail?sid=92929545c283-41b6-9da7$\underline{863 \mathrm{a} 25708989 \% 40 \text { sessionmgr4004\&vid=0 \&hid }=4104 \& \text { bdata }=J n N p d G U 9 Z W h v c 3 Q t}$ bGl2ZQ\%3d\%3d\#db=bth\&AN=5294379 (accessed 16 December 2014). 
Flinn, A. (2007), 'Community histories, community archives: Some opportunities and challenges', Journal of the Society of Archivists, Vol. 28 No. 2, 151-176. Retrieved from: doi: 10.1080/00379810701611936 (accessed 21 September 2015).

Fulton, C. (2009), 'The pleasure principle: The power of positive affect in information seeking', Aslib Proceedings: New Information Perspectives, Vol. 61 No. 3, pp. 245261.

Hassan, D. (2011), 'Prologue: The Cultural significance and global importance of motor sport', The International Journal of the History of Sport, Vol. 28 No. 1, pp.187-190. Retrieved from: doi:http://www.tandfonline.com/doi/full/10.1080/09523367.2011.537908 (accessed 27 October 2015).

Hassan, D. and O'Kane, P. (2011), 'The great race across the Sahara: A history of the Paris to Dakar Rally and its impact on the development of corporate social responsibility within motor sport', The International Journal of the History of Sport, Vol. 28 No. 1, pp. 268-280.

doi:http://www.tandfonline.com/doi/full/10.1080/09523367.2011.537917

Harrington, M., Cuskelly, G. and Auld, C. (2000), 'Career volunteering in commodity intensive serious leisure: Motorsport events and their dependence on volunteers/amateurs', Journal: Loisir et Société / Society and Leisure, Vol. 23 No.2, pp. 421-452. Retrieved from: doi:http://www.tandfonline.com/doi/abs/10.1080/07053436.2000.10707538?journalC ode $=$ rles20 (accessed 27 October 2014).

Hawkins, F. and Blake, M. (2013), 'Victorian collections: Measuring the impact of a digital community museum project', in Museums and Web Asia 2013 proceedings of Museums and the Web in Hong Kong, 8 to 12 December 2013 and Beijing, 14 to 15 December 2013, Hong Kong and China, Beijing.

International Organisation for Standardisation. (2016), ISO 15489-1: Information and documentation - records management - Part 1 - general. International Organisation for Standardisation, Geneva.

Joseph, P., May, S. and Gregg, M. (2013). 'Digitisation of the WA Welcome Wall collection: A case study', Archives and Manuscripts, Vol. 41 No. 3, pp. 183 - 202, doi: 10.1080/01576895.2013.829752 (accessed 29 October 2013). 
Joseph, P. (2015). An exploration of community-based organisation's information management challenges. Proceedings of ISIC: the Information Behaviour Conference, Leeds, 2-5 September, 2014: Part 2, (paper isicsp15), 20(1). Retrieved from: http://www.informationr.net/ir/20-1/isic2/isicsp15.html\#.VRDGu-G6Rq0 (accessed 24 March 2015).

Joseph, P. (2016). Australian motor sport enthusiasts' leisure information behaviour. Journal of Documentation, 72(6), ?-?

Knight, M. and Torre, I. (2013), F1 perfects formula for financial success. Retrieved from http://edition.cnn.com/2013/07/30/sport/motorsport/f1-money-billion-dollar-business/ (accessed 27 October 2015).

Margree, P., MacFarlane, A., Price, L. and Robinson, L. (2014), 'Information behaviour of music record collectors', Information Research, Vol. 19 No. 4, Paper 652, Retrieved from http://www.informationr.net/ir/19-4/paper652.html\#.VmawasqjTqs (accessed 10 December 2014).

Mander, D. (2009), 'Special, local and about us: The development of community archives in Britain', in J. A. Bastian and B. Alexander (Eds.), Community archives: The shaping of memory, Facet Publishing, London, pp. 29-46.

Merriam, S. B. (2009), A guide to design and implementation. John Wiley \& Sons, Inc., USA.

Newman, J. (2010), Sustaining community archives. (Master of Philosophy Master Thesis), Victoria University of Wellington, Victoria. Retrieved from http://researcharchive.vuw.ac.nz/handle/10063/1398 (accessed 1 October 2014).

O'Kane, P. (2011), 'A history of the 'Triple Crown' of motor racing: The Indianapolis 500, the Le Mans 24 Hours and the Monaco Grand Prix', The International Journal of the History of Sport, Vol. 28 No. 1, pp. 281-299. Retrieved from doi:http://www.tandfonline.com/doi/full/10.1080/09523367.2011.537920 (accessed 27 October 2015).

Pflugfelder, E. H. (2009), 'Something less than a driver: Toward an understanding of gendered bodies in motorsport', Journal of Sport and Social Issues, Vol. 33 No. 4, pp. 411-426.

Ross, S. R., Ridinger, L. L. and Cuneen, J. (2009), 'Drivers to divas: Advertising images of women in motorsport', International Journal of Sports Marketing and Sponsorship, Vol. 10 No. 3, pp. 204-214.

Page 24 of 26 
Seven West Media Limited. (n.d.). V8s on seven dominate with the Supercheap Auto Bathurst 1000. Retrieved from http://sevenwestmedia.com.au/docs/business-unitnews/6433B4D8ED14539A82E95679AAF8503AEF47.pdf?sfvrsn=1 (accessed 19 June 2014),

Shackleford, B. (2011). 'NASCAR stock car racing: Establishment and Southern Retrenchment', The International Journal of the History of Sport, Vol. 28 No. 1, pp. 300-318. doi:http://www.tandfonline.com/doi/full/10.1080/09523367.2011.537922 (accessed 27 October 2015).

Skov, M. (2013). 'Hobby-related information-seeking behaviour of highly dedicated online museum visitors', Information Research, Vol. 18 No. 4. Retrieved from http://www.informationr.net/ir/18-4/paper597.html\#.UzPx6IVdBns (accessed 8 January 2014).

SAI (Standards Australia International). (2016). AS ISO 15489.1: Records management Part 1 - general. Sydney: Standards Australia International Ltd.

SAI (Standards Australia International. (2002). AS ISO 15489.2: Records management - Part 2 - guidelines. Sydney: Standards Australia International Ltd.

Stebbins, R. A. (2007), Serious leisure: A perspective for our time. Transaction Publishers, New Brunswick, N.J.

van Leeuwen, A. (2015). Bathurst 1000 worth $\$ 5.25$ million per day - report. Retrieved from http://au.motorsport.com/v8supercars/news/bathurst-1000-worth-5-25-million-perday-report/ (accessed 26 October 2015).

Williamson, K., Bow, A., Charles Sturt University, Centre for Information Studies, and et al. (2002). Research methods for students, academics and professionals: Information management systems (2nd ed.). Centre for Information Studies, Charles Sturt University, New South Wales, Australia.

Yakel, E. (2004), 'Seeking information, seeking connections, seeking meaning: genealogists and family historians', Information Research, Vol. 10 No. 1. Retrieved from http://InformationR.net/ir/10-1/paper205.html (accessed 15 March 2013).

Yin, R. K. (2009), 'How to do better case studies (with illustrations from 20 exemplary case studies)', in L. Bickman and D. J. Rog (Eds.), The SAGE handbook of applied social research methods (2nd ed.), Sage Publications, London, pp. 254-282.

Yin, R. K. (2012), Applications of case study research (3rd ed.), Sage Publications, London. 
Yin, R. K. (2014), Case study research: Design and methods (5th ed.), Sage Publications, London.

Page 26 of 26 


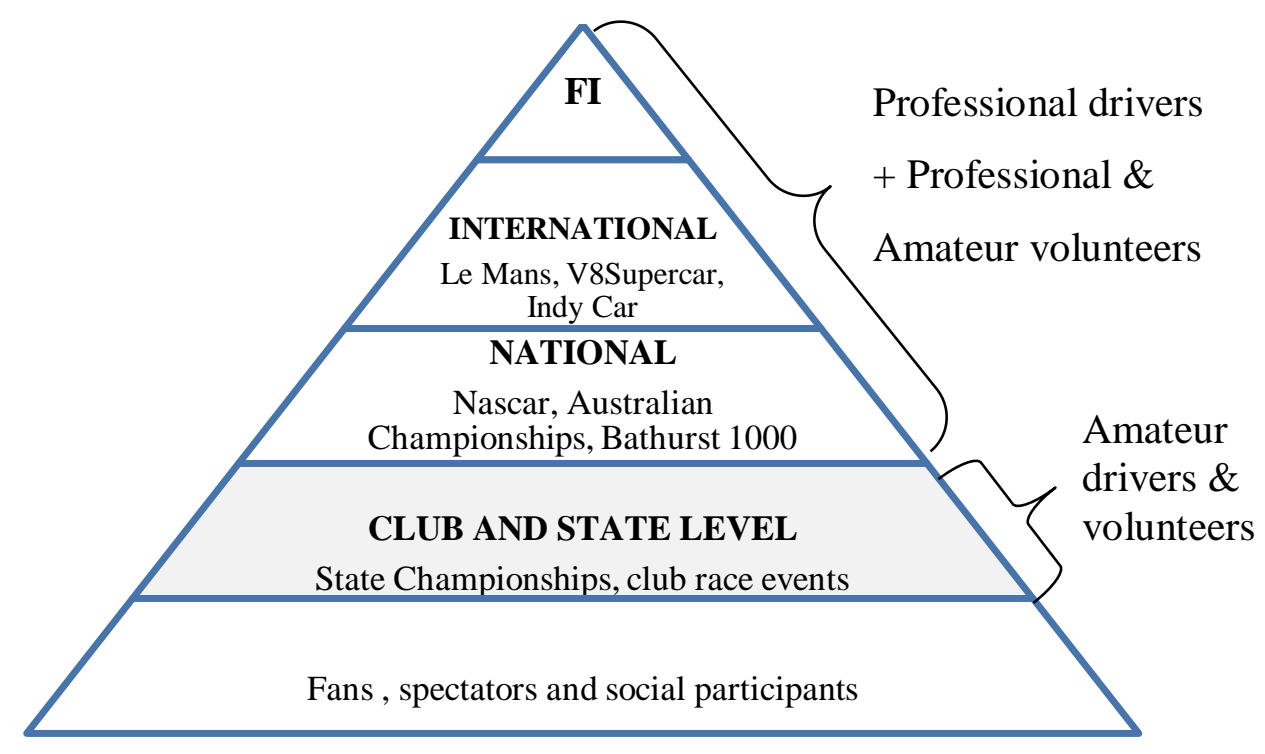

Figure 1: Pyramid metaphor to describe motor racing internationally

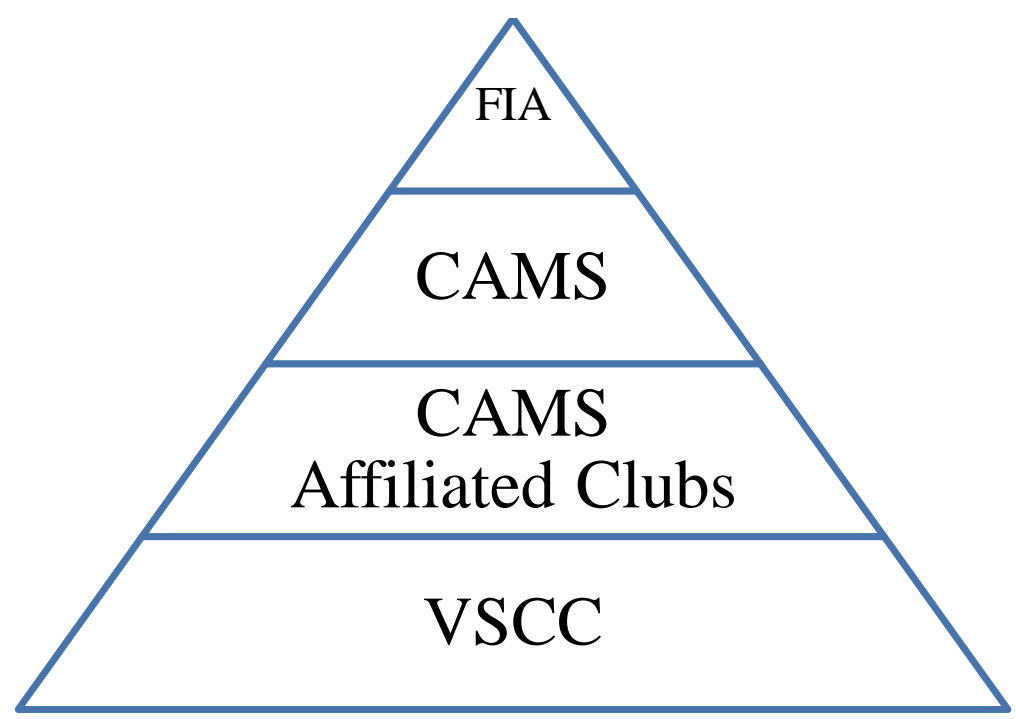

Figure 2: Pyramid metaphor to describe motor sport community in Australia 


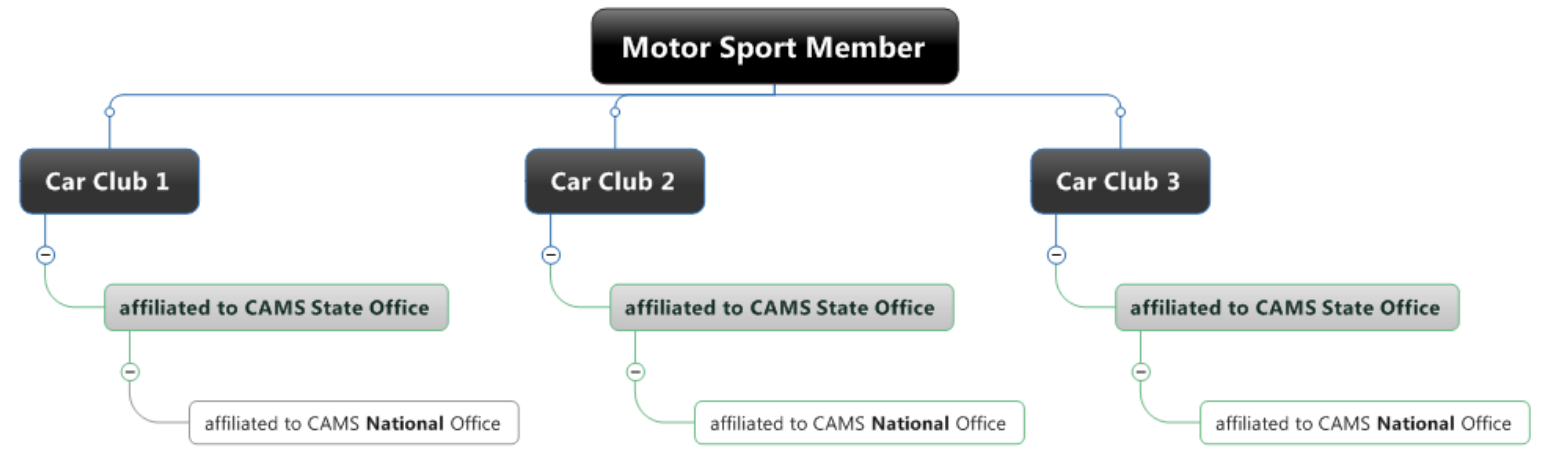

Figure 3: Member relationship to clubs and CAMS

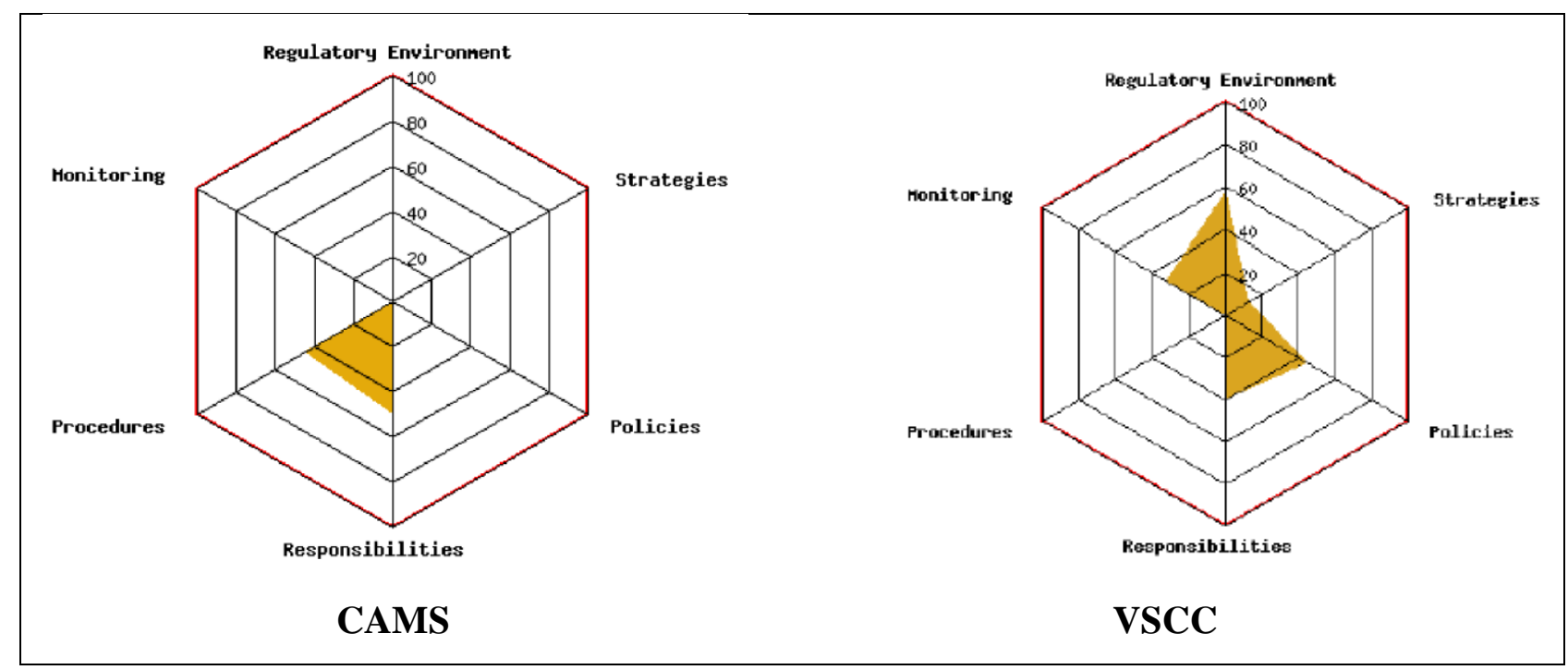

Figure 4: Governance summary of records management programme 


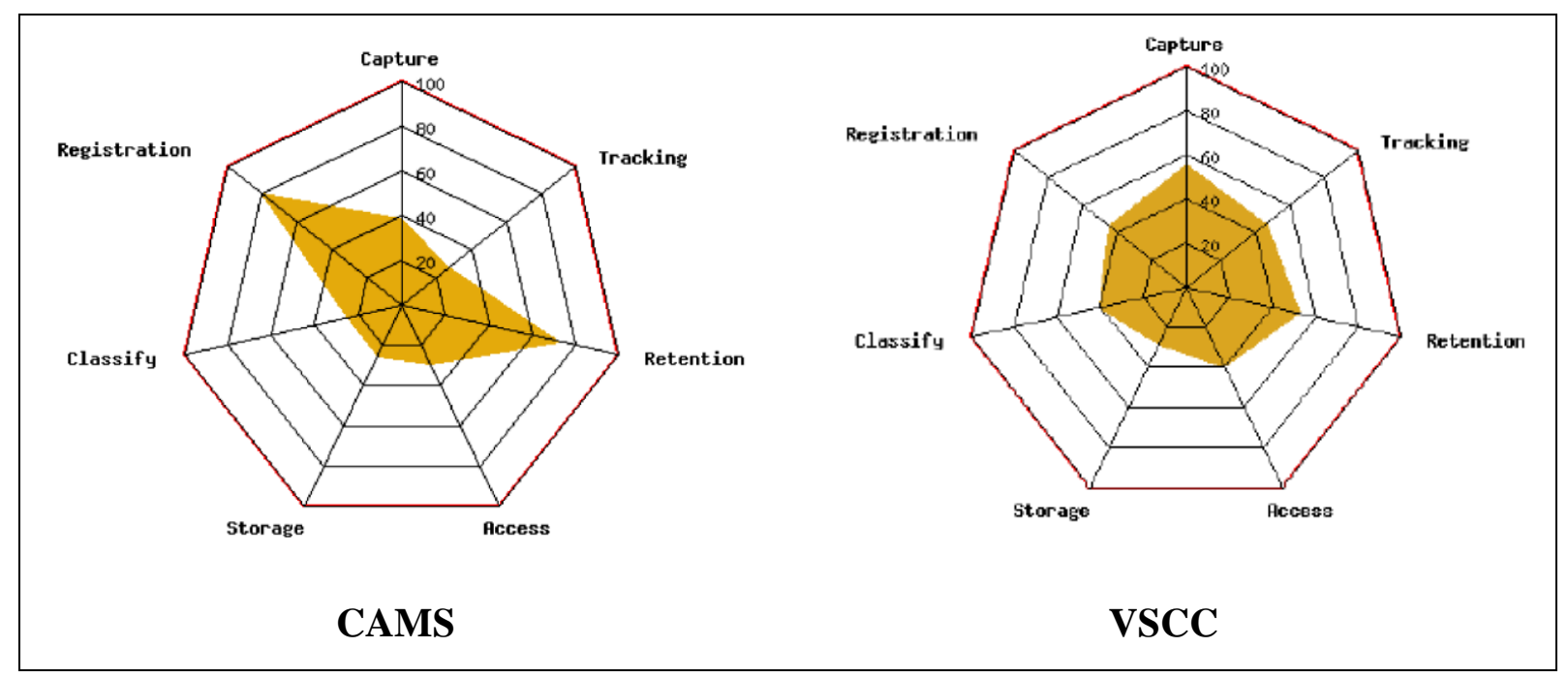

Figure 5: Records management process summary

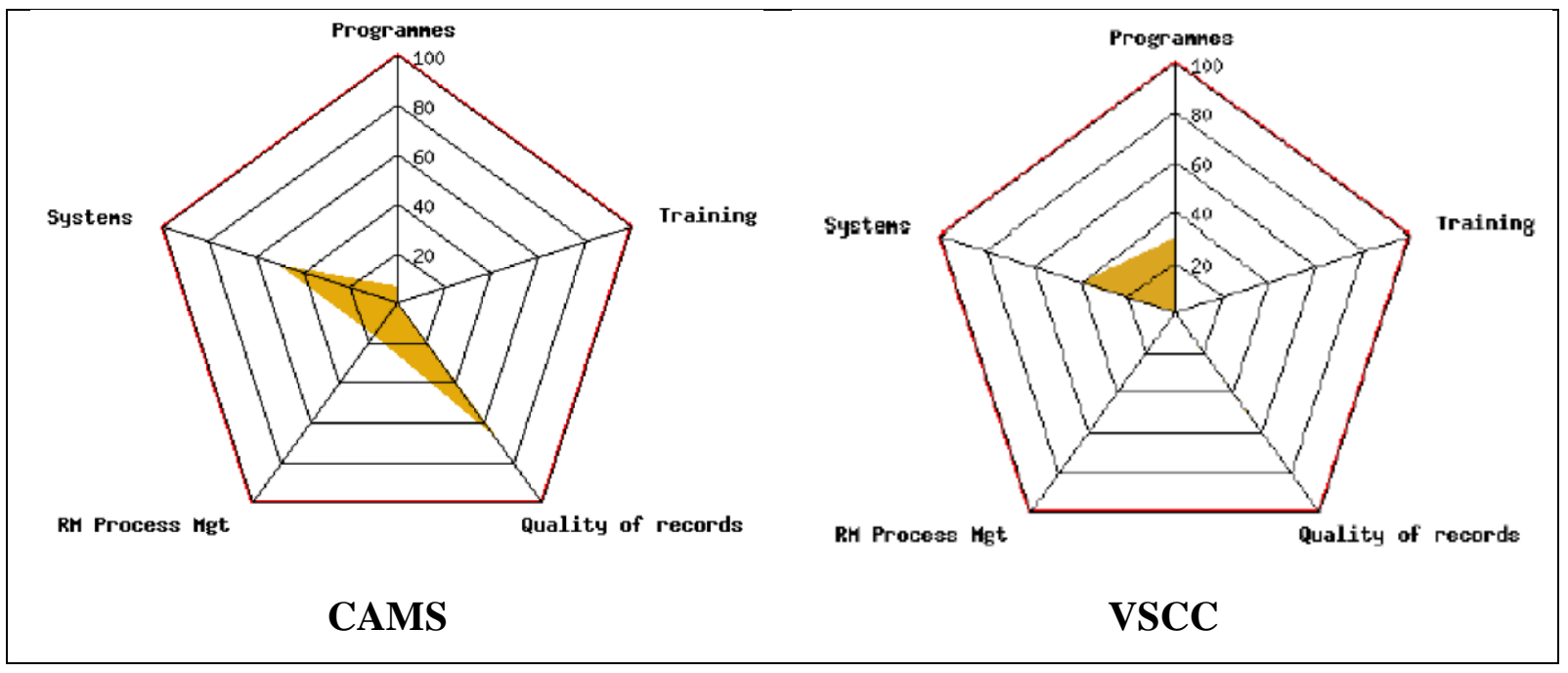

Figure 6: Programme management summary 


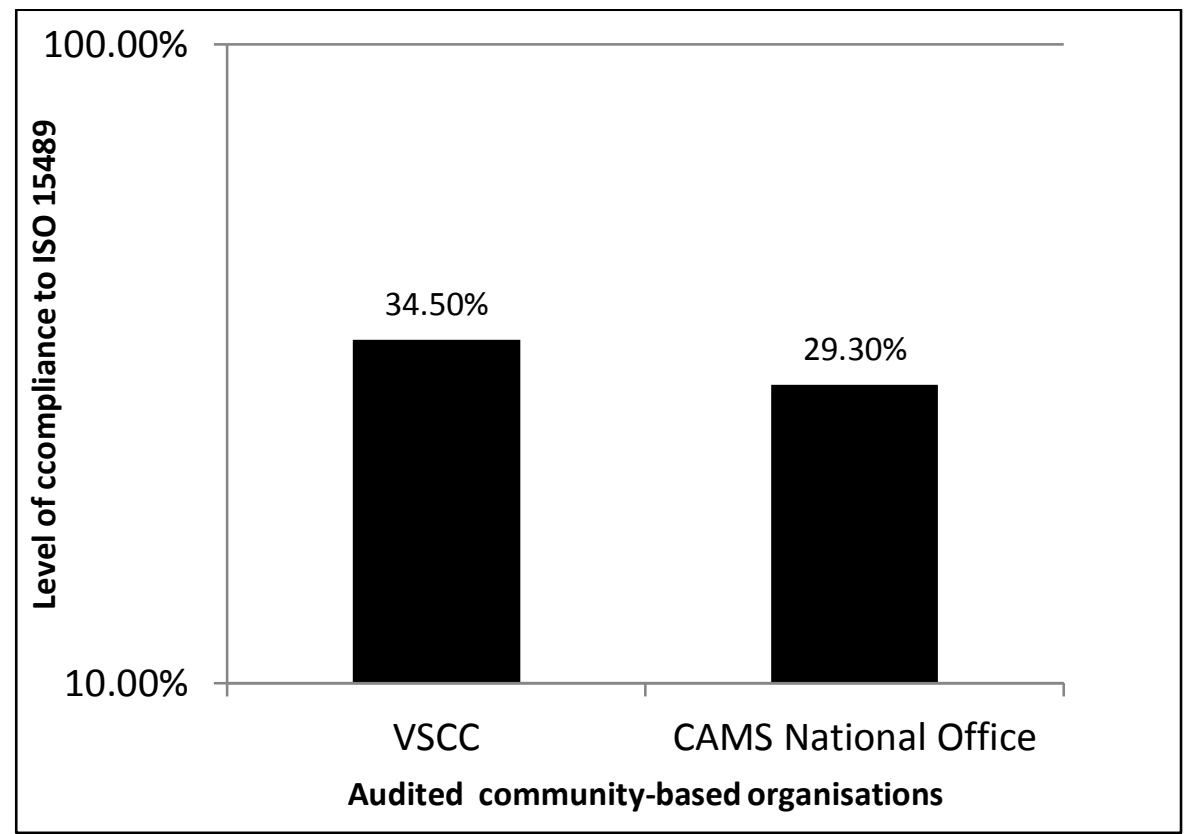

Figure 7: Overall conformance with all clauses of ISO 15489 
Table 1: Snapshot of research framework

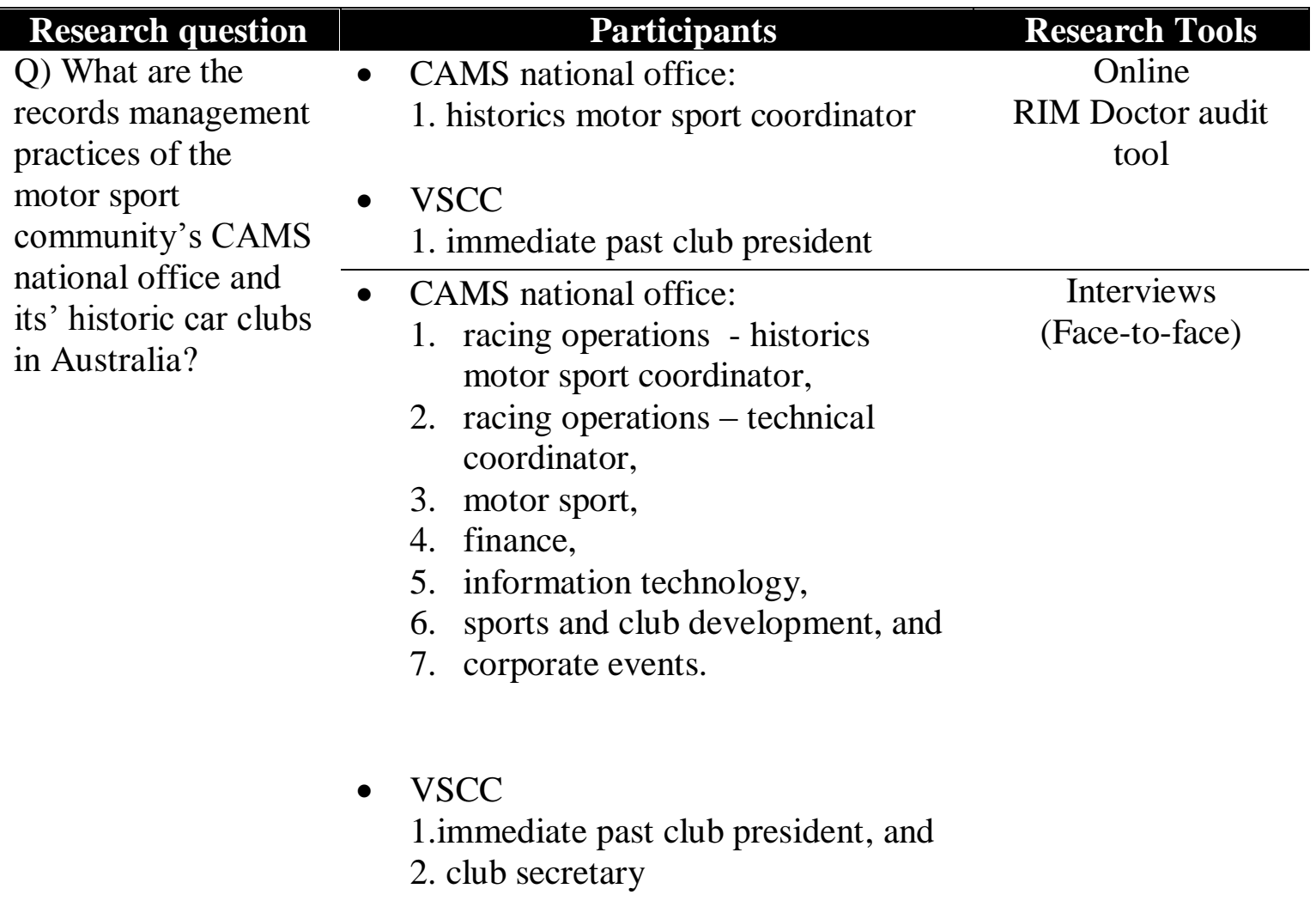

